Revue de I'IFHA

Revue de l'Institut français d'histoire en Allemagne

$4 \mid 2012$

IFHA 4

\title{
« Frankreich für Historiker » ou Faire de l'histoire en France pour les chercheurs allemands
}

\section{Pierre Monnet}

\section{OpenEdition}

\section{Journals}

Édition électronique

URL : http://journals.openedition.org/ifha/414

DOI : $10.4000 /$ ifha. 414

ISSN : 2198-8943

\section{Éditeur}

IFRA - Institut franco-allemand (sciences historiques et sociales)

\section{Édition imprimée}

Date de publication : 30 septembre 2012

Pagination : 93-95

ISSN : 2190-0078

\section{Référence électronique}

Pierre Monnet, « «Frankreich für Historiker » ou Faire de l'histoire en France pour les chercheurs allemands », Revue de l'IFHA [En ligne], 4 | 2012, mis en ligne le 14 février 2013, consulté le 23 avril 2019. URL : http://journals.openedition.org/ifha/414 ; DOI : 10.4000/ifha.414

Ce document a été généré automatiquement le 23 avril 2019

(CIFHA 


\title{
« Frankreich für Historiker » ou Faire de l'histoire en France pour les chercheurs allemands
}

\author{
Pierre Monnet
}

1 Le 18 juin 2012 une table ronde s'est tenue à Paris, dans les locaux de l'Institut historique allemand de Paris (IHAP), pour mettre en œuvre la publication d'un guide de la recherche historique française à destination des chercheurs de langue allemande, puisque ce scholar guide sera publié en allemand. Cette manifestation, qui a réuni 11 auteurs et chercheurs historiens français et allemands autour des trois éditeurs du guide, Falk Bretschneider (CRIA/EHESS), Mareike König (IHAP) et Pierre Monnet (EHESS/IFHA), a été financée par le programme franco-allemand de la Maison des sciences de l'homme, l'IHAP et coorganisée par l'IFHA. À l'automne 2011, en effet, était mis en ligne sur la plateforme Perspectivia.net, la plateforme de publication en sciences sociales et humaines des instituts allemands de recherche à l'étranger (Paris, Londres, Moscou, Rome, Varsovie, Washington, Tokio, Beyrouth, Istanbul), un guide intitulé «Faire de l'histoire en Allemagne » à destination des chercheurs historiens de langue française (http:// www.perspectivia.net/content/publikationen/scholar-guide/histoire-en-allemagne).

2 Ce guide, de quelque 300 pages et 13 articles, dirigé par Falk Bretschneider et Mareike König, entendait présenter les ressources tant institutionnelles et financières que documentaires, professionnelles, scientifiques et humaines, les outils, les structures et les pratiques de la recherche allemande en adoptant le regard du chercheur français soucieux d'entrer en contact avec la recherche allemande, d'y effectuer un séjour en archives ou en bibliothèque, d'y étudier, d'y publier, voire d'y faire carrière. Il s'agissait donc, dans une perspective quasi "ethnographique» d'expliquer aux chercheurs francophones les spécificités, les habitus, les particularités voire les étrangetés du dispositif allemand des études historiques, dans un pays où la compétence scientifique et académique est avant tout du ressort des régions, où la publication du doctorat est obligatoire pour obtenir un titre intégré ensuite dans l'état civil de son détenteur, où les instituts et les fondations extra-universitaires occupent une place centrale dans le 
financement et les carrières scientifiques, où le classement des archives diffère d'une ville et d'un Land à l'autre, où les cursus d'études sont encore loin d'être tous " bolognisés ", où les découpages entre périodes et disciplines suivent d'autres frontières, où la langue scientifique des études historiques obéit à d'autres règles et d'autres normes. C'est ainsi qu'après une présentation des grandes tendances actuelles de la recherche historique en Allemagne (Étienne François), les structures de la recherche historique en Allemagne étaient abordées (Falk Bretschneider, Bernd Klesmann, Rahul Markovits), puis les études d'histoire en Allemagne (Gabriel Lingenbach), puis la thèse de doctorat (Falk Bretschneider et Christophe Duhamelle), puis les archives en Allemagne (Falk Bretschneider et Juliette Guilbaud), puis les revues historiques (Christophe Duhamelle), suivies des bibliothèques en Allemagne (Mareike König), des ressources électroniques (Mareike König et Annette Schläfer), de la préparation (Patrick Farges) et du financement (Peggy Rolland et Claire Vital) d'un séjour scientifique en Allemagne, pour s'achever par l'écriture de l'allemand scientifique (Elisabeth Venohr, Sébastien Rival), la publication de la thèse (Claudie Paye) et le métier d'historien (Elissa Mailänder-Koslov).

3 Le nouveau guide lancé par la manifestation du 18 juin 2012 est donc conçu comme le pendant ou le jumeau du précédent. Bénéficiant de l'expérience et du savoir-faire capitalisés par les deux éditeurs Falk Bretschneider et Mareike König, il entend rendre les mêmes services suivant le même regard tiers porté sur un dispositif français des études et de la recherche historiques marqué par l'importance à tous les niveaux des concours de recrutement nationaux, par un pilotage centralisé par le Ministère et les grandes agences, par une normalisation nationale des cotes d'archives, par la bipolarité entre les universités d'un côté et les grandes écoles de l'autre, par la concentration et la surreprésentation du pôle parisien, par le caractère quasi sanctifié du binôme entre histoire et géographie. La table des matières du précédent guide a servi de support pour établir celle du présent guide projeté, tant elle avait semblé à l'usage avoir fait ses preuves. Elle comprendra donc un panorama des tendances actuelles de la recherche française, l'exposé des structures de la recherche en France, les cursus d'études, la thèse (et la cotutelle), le classement et l'organisation des archives, les grandes revues, les bibliothèques, les ressources électroniques et les portails internet, le financement et la préparation d'un séjour de recherche en France, l'écriture et la rhétorique scientifiques en français, la publication et les perspectives professionnelles pour un jeune historien en France. Toutefois, par rapport au guide en français pour chercher et étudier en Allemagne, ce guide en allemand pour étudier et chercher en France sera enrichi de deux chapitres supplémentaires, l'un consacré à la formation, au recrutement et à la carrière des enseignants d'histoire en France (rôle des classes préparatoires, extension des classes européennes et Abibac, concours du Capes et de l'agrégation...) et l'autre aux musées (et singulièrement aux musées d'histoire).

4 Le calendrier de parution de ce guide prévoit sa mise en ligne électronique à l'automne 2013, sur le site de l'IFHA dont les publications (le Bulletin puis la Revue et la base des recensions parues dans ces périodiques) sont en voie de numérisation et de migration sur un site dédié du portail http://www.revues.org. 


\section{AUTEUR}

\section{PIERRE MONNET}

Pierre Monnet est directeur de l'IFHA. 